\title{
PSYCHE
}

VOL. XIX.

OCTOBER, 1912.

No. 5

\section{THE YELLOW CURRANT FLY OR GOOSEBERRY FRUIT FLY. (EPOCHRA CANADENSIS LOEW.)}

\author{
By John Howard Paine, \\ Stanford University, California. \\ HISTORY AND DISTRIBUTION.
}

The Yellow Currant Fly, or The Currant Fly, as it was called until the appearance in Washington of a similar insect (Rhagoletis ribicola Doane $)^{1}$ affecting the same hosts made the use of a more specific name necessary, was first described by Loew in 1873 from a single faded specimen contributed by Osten Sacken. The type locality is either Canada or Maine, Osten Sacken giving Norway, Maine, as the locality for his material and Loew giving Canada as a locality upon the authority of Mr. Provancher. One cannot say how long the species may have been known before its description, and Osten Sacken says that it "seems to be common in those regions." If he knew of its currant-infesting habits, no mention was made of them.

In 1883 the Currant Fly was again brought to notice when its currant-infesting habits were recorded for the first time by Saunders, though his knowledge on the subject was apparently slight.

The first detailed account of this species was given by Prof. C. P. Gillette who found it very abundant in Colorado. He noticed the flies ovipositing and observed the eggs under the skin, also stating that the affected currants ripened prematurely and dropped to the ground where the maggots remained in them for some time. He recorded one brood.

Dr. F. L. Harvey in 1895 gives us the most detailed account of the Currant Fly and its habits, with numerous figures. $\mathrm{He}$ records it as abundant in Maine, Washington and British Colum-

\footnotetext{
${ }^{2}$ Piper and Doane, Insects Injurious to Currants and Gooseberries. Bull. 36. Wash. Ag. Exp. Sta. 1898.
} 
bia, and states that Epochra canadensis Loew is quite certainly a native American species, distributed throughout the northern part of the United States and in Canada, extending from the Atlantic to the Pacific slope.

The following notes were taken from observations of the Yellow Currant Fly made in the vicinity of Stanford University. The data here recorded refer to the fly only in the San Francisco Bay region, its habits elsewhere being unknown to the writer from personal observation.

\section{LIFE HISTORY AND HABITS.}

\section{The Egg; Its Deposition.}

The egg (Plate 11, fig. 2) of the Currant Fly is oblong, shining opalescent white, with a short pedicle at one end. This pedicellate end is finely sculptured in a.hexagonal pattern for about one third the length of the egg, giving it a pitted appearance, as shown in the photograph. The egg, measuring slightly over one millimeter, is plainly visible, as a rule, lying directly under the epidermis of the stung fruit with the pedicellate end near the puncture (Plate 11, fig. 3). The adult flies were first observed in Palo Alto on April thirteenth; they probably issued several days earlier. Specimens were sent to the laboratory from San José which had issued on April eighth. The habits of the adult female are very interesting, a constant fluttering of the wings and continual running around in circles on the berries being quite characteristic. As a rule in egg-laying, the fly may prefer a berry that has not been stung before, but among the fruit under observation most of the berries had been stung twice and usually oftener. One case was noted where three eggs lay within a quarter of an inch of each other. When ready to oviposit, the insect comes to rest on the fruit with legs well braced, turns the last three segments with the ovipositor under the body at an angle of about forty-five degrees and makes a puncture in the epidermis (Plate 10).

The time consumed in depositing an egg varies greatly, the maximum period noted being fifteen minutes and the minimum a minute and a half; the usual time consumed is about three minutes. After puncturing the epidermis a long cavity is formed directly 
underneath the skin, the ovipositor being worked back and forth with a pumping movement accompanied by a constant and rapid movement of the mouth-parts. The result of an attack upon a berry is at first visible only upon close examination, but in a few days the area about the egg turns brown and makes a very conspicuous spot with dark edges as may be seen in Plate II, fig. 3. These spots are also visible in Plate 10.

In the vicinity of Stanford University egg laying continued throughout the mouth of April and till about the middle of May. By that time scarcely a currant or gooseberry could be found that had not been badly affected.

\section{The Larva and Its Development.}

After a period of incubation lasting, in the case of specimens taken into the laboratory, for eleven days, the minute white larva or maggot hatches and begins to burrow in the pulp, often following a winding path for some little distance before making its way into a seed. These twisting burrows may often be observed from the exterior. The larva is white, its footless body consisting of about thirteen segments. Protruding from the mouth are two conspicuous black chitinous hooks, the rasping organs, by means of which it gnaws its way through the fruit. This maggot when mature measures about seven millimeters in length. As it continues feasting upon the juicy fruit, its quarters within the seed become cramped, and it then leaves the seed to feed upon the surrounding tissue. The presence of the larva causes the berries to ripen and drop prematurely; they turn red, with unsightly black blotches caused by the decaying matter within the fruit. As soon as the fruit drops, the larvae, if full grown, issue and make their way into the ground. Often, however, they have not attained their full size, in which case they remain within the fallen fruit until mature. According to some observers the larvae may leave the berries before the latter drop to the ground; this however, was not observed by me.

Although nearly all of the currants had several eggs deposited in them, in no instance was more than one mature larva found in a berry; in one case one half-grown and one small maggot were discovered in the same fruit. 


\section{The Pupa.}

After the larva has penetrated the ground to the depth of an inch or two, or perhaps more, it changes to the pupal condition. The pupa is straw colored and rather hard, measuring about five millimeters. Throughout this stage the insect is, of course, inactive and remains in the ground until the following spring. This fact has suggested some of the methods of control that have been recommended.

\section{The Adult.}

There appears to be but one brood, the insects remaining in the ground as inactive pupae for ten months. The writer has not had opportunity to observe this personally, but it seems unlikely that a second brood would have escaped notice for so many years. It is reported that growers state that they obtain a second crop of currants after the insects have disappeared. The only evidence that suggests a second brood, is the report of a single specimen of Epochra canadensis collected at Redwood City late in the summer.

As stated above the adults appear about the second week in April and remain near the currant and gooseberry bushes for about a month. The males appear in less numbers than the females, but this may be due to the fact that the former do not confine themselves so closely to the bushes. Numbers of males were found upon the limbs of a nearby apricot tree. They show the same restless habits as the females, running about over the bush with wings a-flutter and often with the mouthparts and transparent sides of the abdomen distended. On the bushes they seem to show no preference for the fruit, as do the females, but are often found upon the stems.

Where the adults pass the night was not discovered. A careful search of the currant and gooseberry bushes and of neighboring shrubs and trees in the morning failed to locate the insects. Often they do not appear in the morning till ten o'clock, especially if the weather is cloudy. The adult insect is rather variable in size, the average specimen being about as large as the common housefly. It may be recognized about currant and gooseberry bushes during the last half of April and first part of May by its pale yellow or orange color, green iridescent eyes and wings marked by dark smoky bands (Plate 11, fig. 4). Probably its most notable char- 
acteristic, and the one by which it may be most easily recognized while alive, is the nervous habits previously described. For a complete technical description of the insect the reader should turn to Doctor Harvey's report ('95) on the fly in Maine.

\section{REMEDIAL MEASURES.}

The methods usually recommended are as follows:

1. Frequent burning of fallen currants. If some of the maggots leave the fruit before it falls, this remedy cannot be relied on to destroy all the flies. However, in fighting a pest it is often the application of a series of control measures which becomes effective.

2. The removal of the top soil underneath the bushes to a depth of two or three inches and placing the same in a traveled roadway or burying it deep would destroy the pupae in the ground. This, of course, should be done only after the crop has entirely gone.

3. A mulch of coarse straw or hay under the bushes, well packed, might hinder the flies from emerging. The efficiency of this remedy is doubtful.

4. Allowing young chickens to run under the bushes at the time of ripening of the fruit should lessen the numbers of the pests.

5. A measure which seems to have met with approval is to pick and destroy the entire crop while green. If there is no fruit in which the flies may lay their eggs they must go elsewhere or perish. This remedy is usually classed as "radical" or "heroical," but the fruit in this vicinity could not be used in any event and might just as well have been destroyed before the larvae had an opportunity to enter the ground. Of course, where the infestation is light, this might not be advisable if part of the crop could be harvested. For most people, however, a few wormy berries in a basket, provided they knew it, would be sufficient to render them unfit for use, unless they did as one discouraged and disgusted lady suggested, "Pickle them and save meat bills"-her fruit was fairly alive with maggots. The trouble with this, as well as with the other remedies, is the fact that if your neighbor has bushes and does not take the same precautions, he will supply you, the following spring, with a bountiful supply of the insects. If, however, no fruit is grown in the vicinity this method should prove effective. 
6. A remedy tried by the writer which proved effective, yielding sound fruit in a heavily infested region, was to cover the entire bush with mosquito netting, thus keeping the flies away from the berries. This should be done immediately after the fruit has set; the fly does not attack very young currants or gooseberries. Plate II, fig. 1 shows stages at which both fruits become infested; the small currants at the end of the cluster have not been stung and should be covered at this stage; the same is true of the smaller gocseberries.

This remedy was tried only on a small scale in gardens where the fruit is grown for table purposes. It is not known whether the method could be applied commercially. One large currant bush required three and one half yards of double width netting costing ten cents a yard. The netting should be tied closely about the base of the bush to exclude the flies. The bush itself may be tied together before applying the net, to make it smaller.

\section{BIBLIOGRAPHY.}

'73. Loew, H. In Smith. Miss. colls. 256. Monograph of the Diptera of N. America. Pt. 3, p. 235. Dec. 1873.

'83. Saunders, W. Insects Injurious to Fruits, 1883, p. 352.

'92. Gillette, C. P. Bull. Colorado Exp. Sta. No. 19, p. 18, May, 1892.

'91. Editors Insect Life. Injurious Insects of 1891 in Colorado. Ins. Life, Vol. 4, p. 355. 1891-2.

'94. Snow, W. A. Kansas Univer. Quar., Vol. 11, No. 3, p. 159, 1894.

'95. Harvey, F. L. The Currant Fly, Goosberry Fruit-Fly. Ann. Rep. State College, Maine, 1895, Pt. 2, p. 111.

'97. Harvey, F. L. The Currant Fly, Gooseberry Fruit-Fly. Bull. 35, Maine Agric. Expt. Sta. 1897. Also in 13th Ann. Rept. Maine Ag. Expt. Sta., 1897, p. 25.

'98. Piper, C. V., and R. W. Doane. Insects Injurious to Currants and Gooseberries. Washington Ag. Exp. Sta. Bull. No. 36, 1898.

'10. Johannsen, O. A. Insect Notes for 1909. Maine Agric. Expt. Sta. Bull. No. 177, p. 36.1910. 


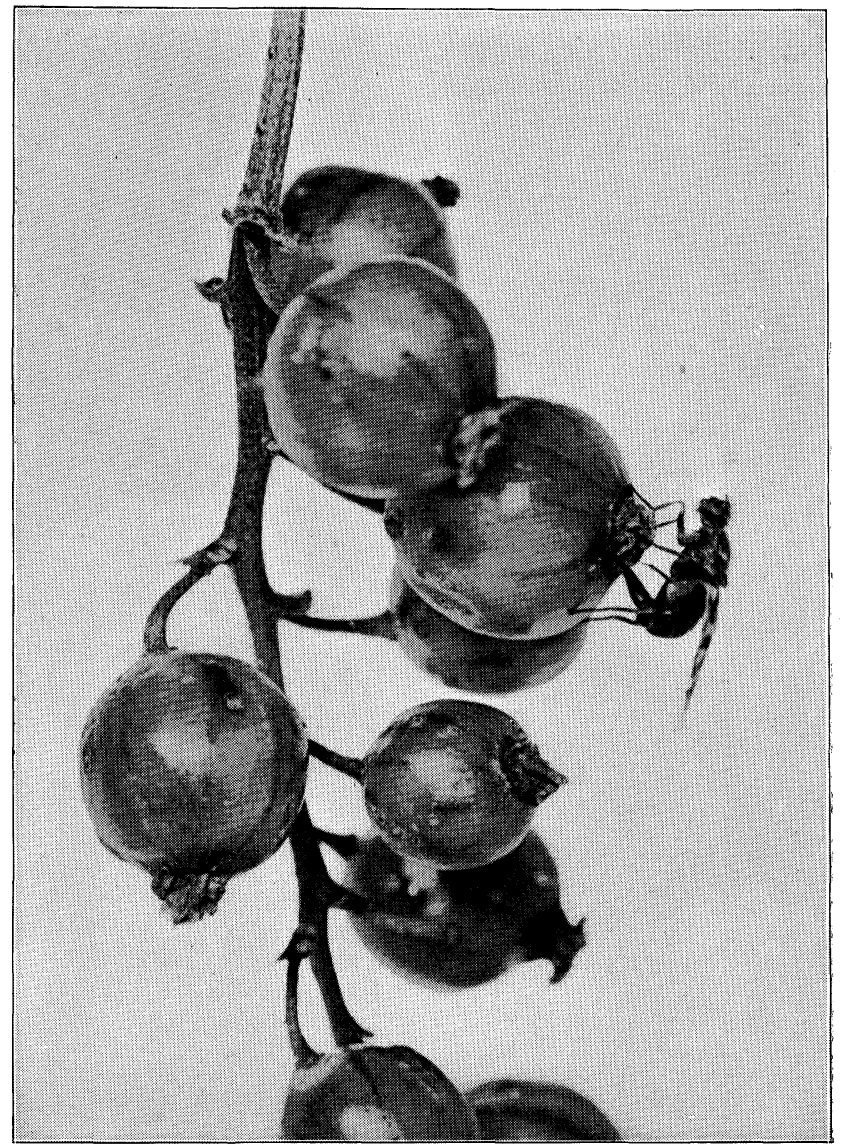

Epochra canadensis Loew, ovipositing in currant.

J. H. Paine, Photo. 


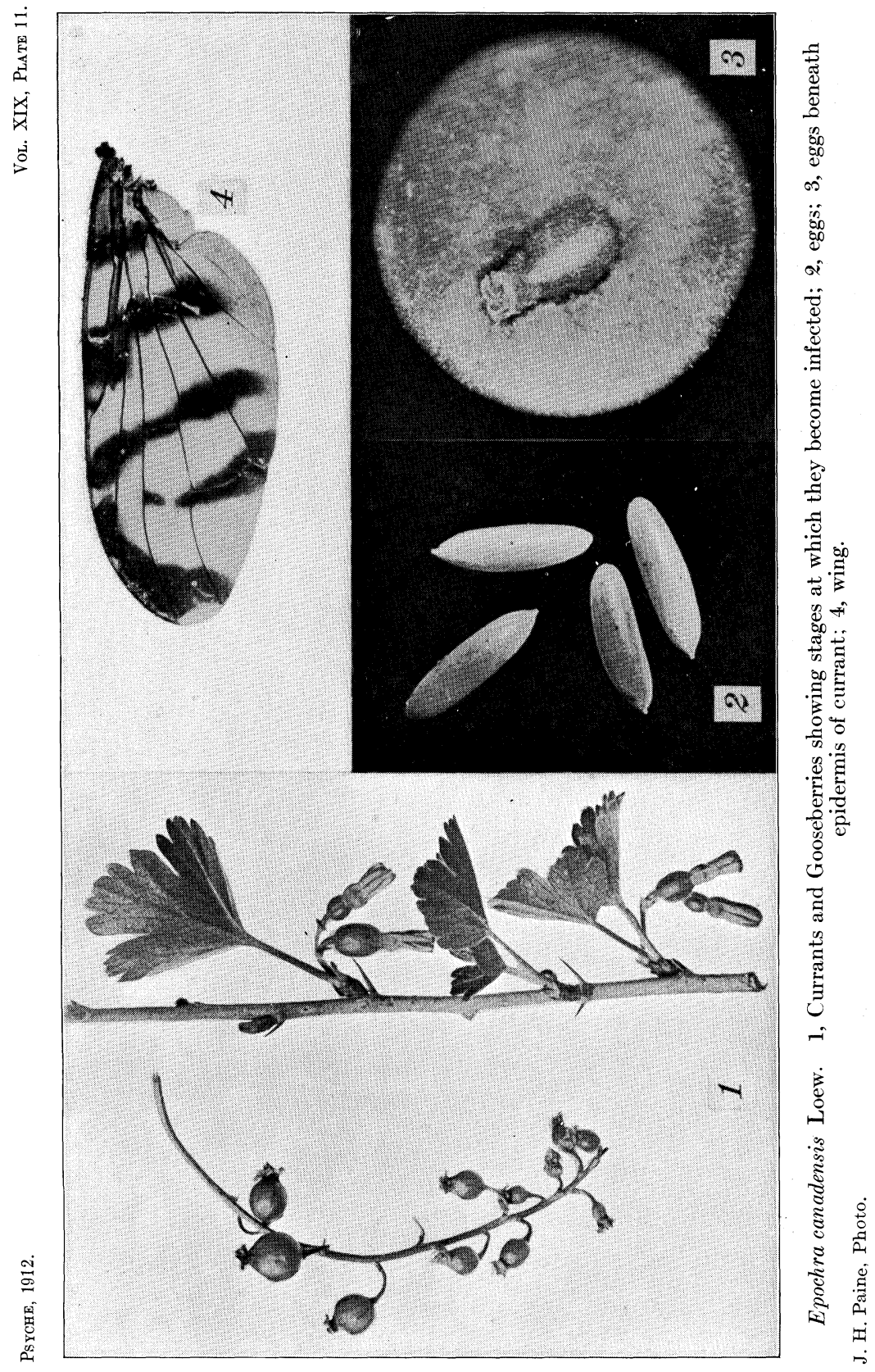



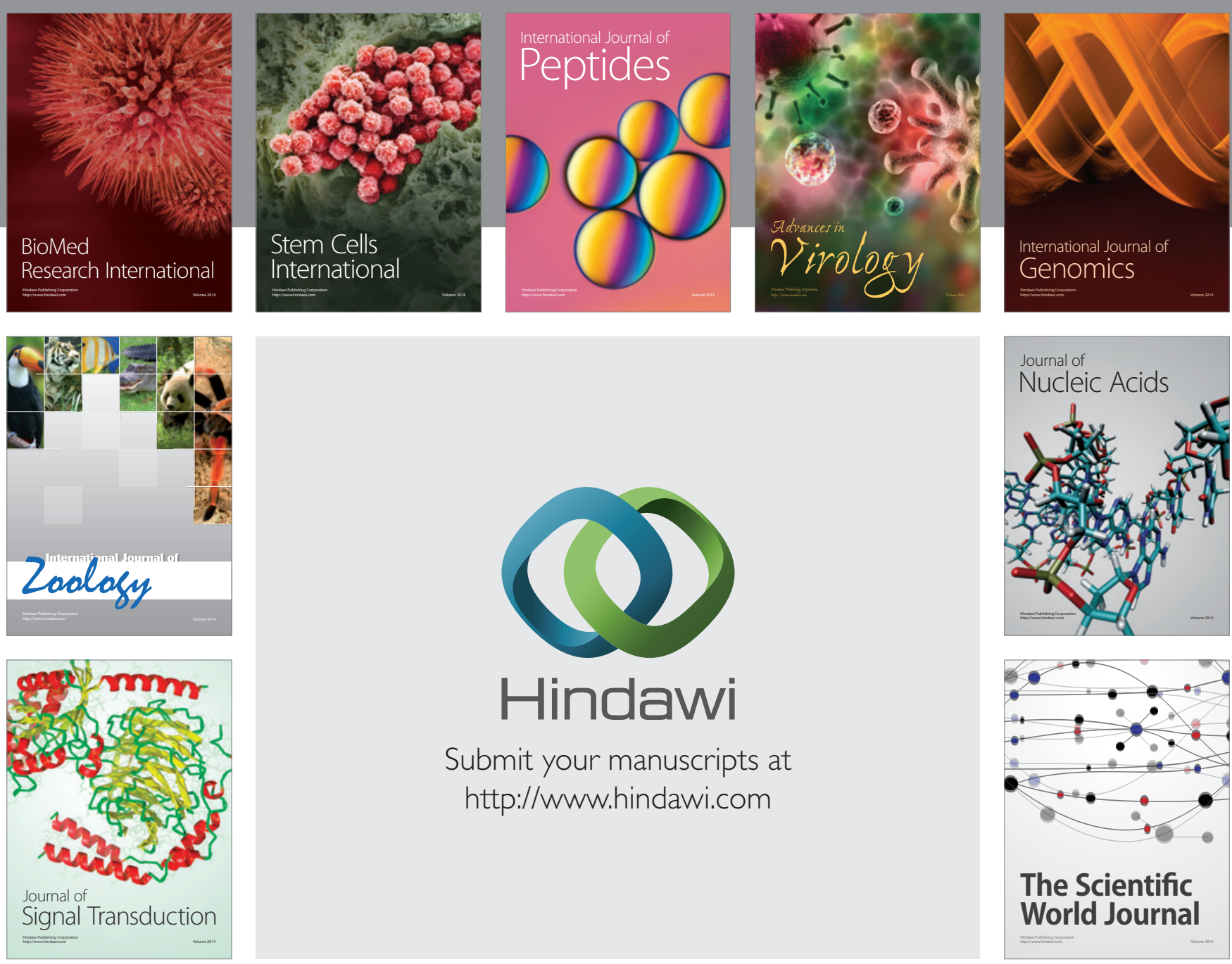

Submit your manuscripts at

http://www.hindawi.com
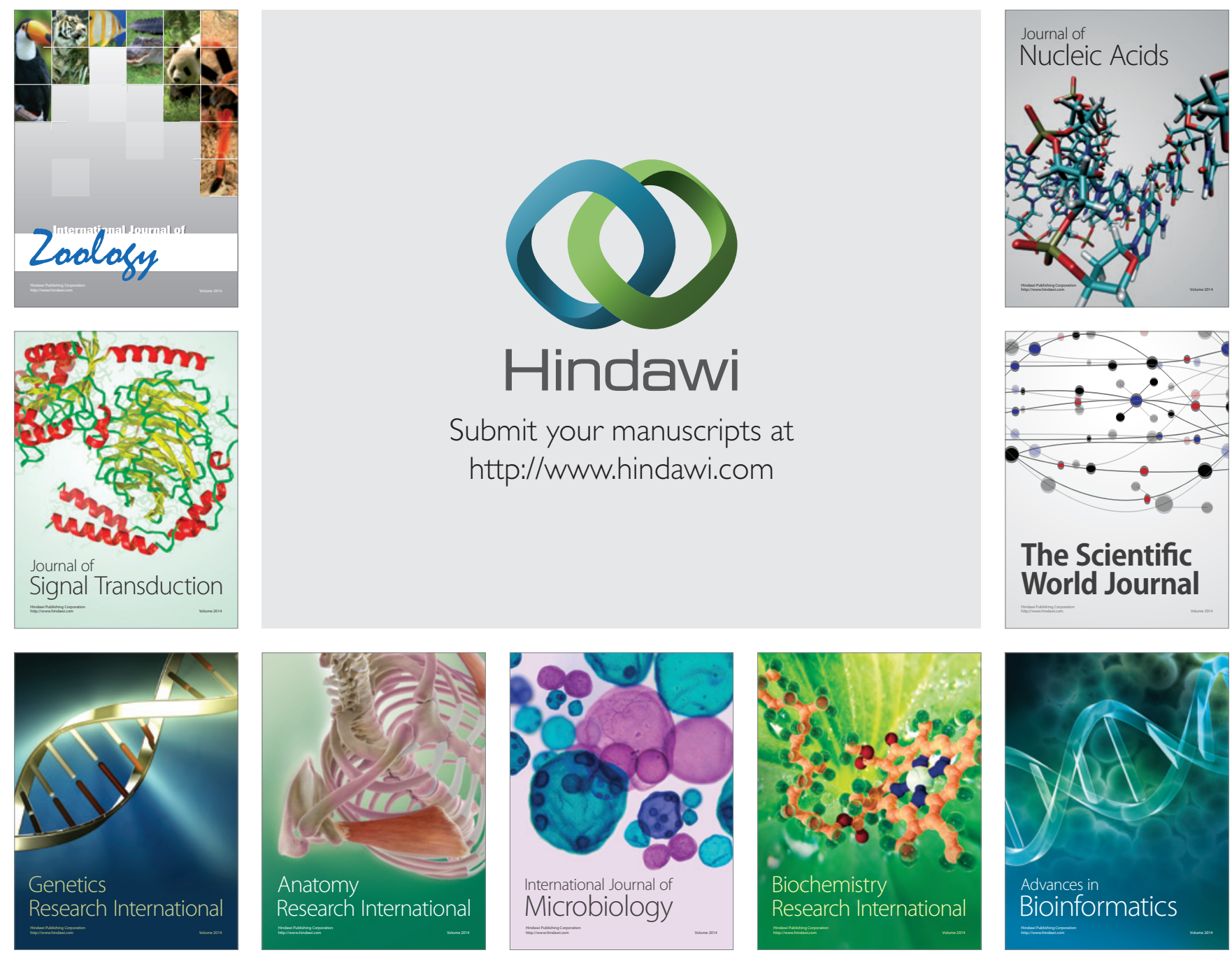

The Scientific World Journal
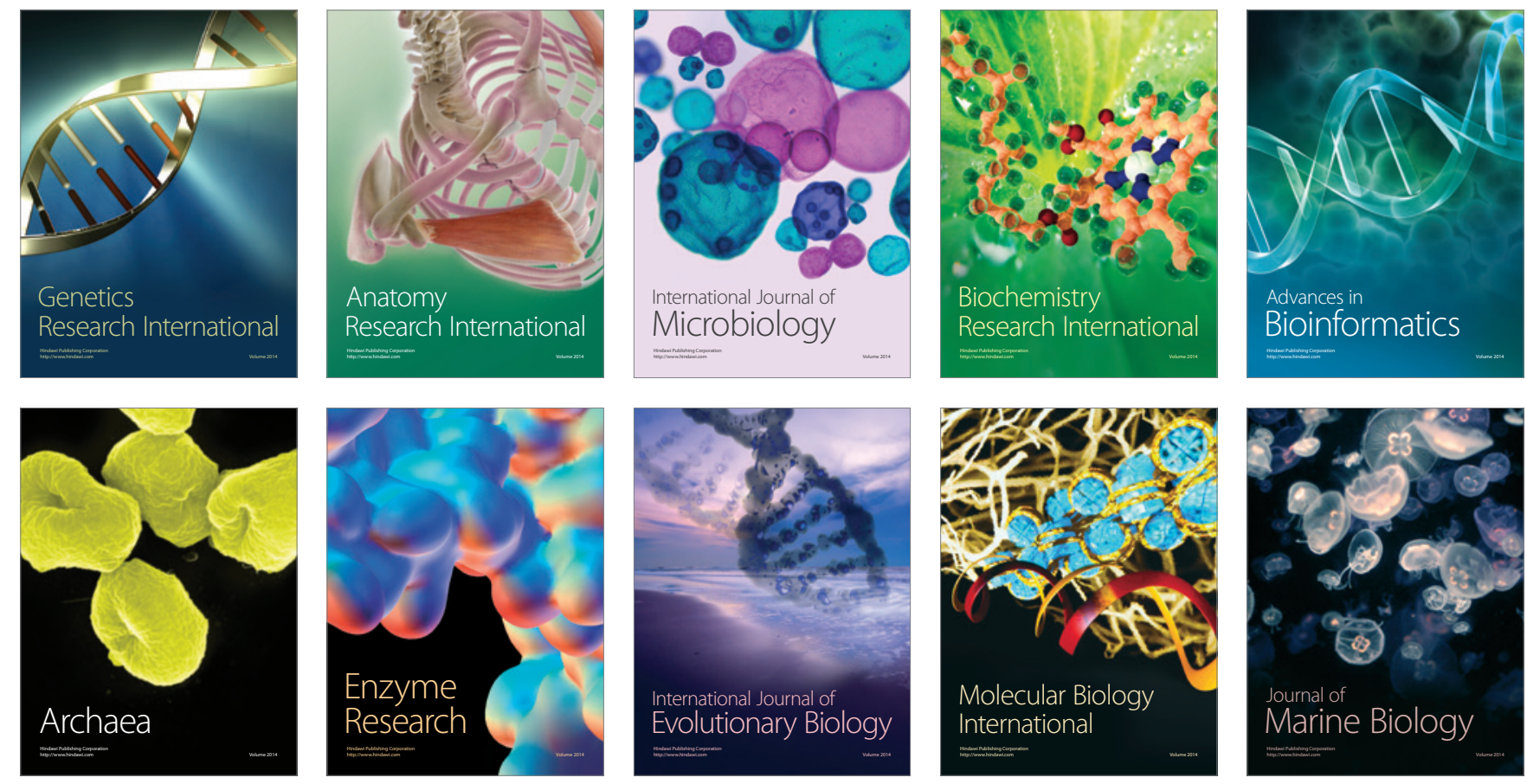